\title{
Zinc Oxide Composites of Doxorubicin in the Form of Coating, Composite Films and Gels with a High Antitumor Activity and Low Toxicity
}

\author{
Emma R. Arakelova1', Stepan G. Grigoryan², Ashot M. Khachatryan¹, Anahit A. Mirzoian"1, \\ Zoya M. Farmazyan" ${ }^{1}$, Susanna L. Grigoryan ${ }^{1}$, Mkrtich A. Yeranosyan ${ }^{3}$, Flora G. Arsenyan ${ }^{2}$, \\ Rafayel E. Muradyan'2, Hrachik V. Gasparyan²
}

\footnotetext{
${ }^{1}$ Scientific Research Division, National Polytechnic University of Armenia (NPUA), Yerevan, Armenia; ${ }^{2}$ Scientific Technological Center of Organic and Pharmaceutical Chemistry (STCOPC), Yerevan, Armenia; ${ }^{3}$ Yerevan State University (YSU), Yerevan, Armenia
}

Correspondence to: Emma R. Arakelova, emma_arakelova@yahoo.com

Keywords: Zinc Oxide, Magnetron Sputtering, Doxorubicin, Composites, Antitumor Activity

Received: February 1, $2019 \quad$ Accepted: March 11, $2019 \quad$ Published: March 14, 2019

Copyright $\odot 2019$ by authors and Scientific Research Publishing Inc.

This work is licensed under the Creative Commons Attribution International License (CC BY 4.0).

http://creativecommons.org/licenses/by/4.0/

\section{(c) (i) Open Access}

\section{ABSTRACT}

This work is devoted to the formation doxorubicin (DOX) zinc oxide composites in the form of coating (DOX $+\mathrm{ZnO}$ ), hydrogels and composite films of DOX with polyvinyl alcohol (DOX + PVA + ZnO) by DC-magnetron deposition of $\mathrm{ZnO}$ nanoscale particles ( $\mathrm{ZnO}$ NPs) on their surfaces (DOX, DOX + PVA) with higher (two times and more) antitumor activity and considerable smaller toxicity at low doses of DOX in compositions compared to the initial drug. Using the methods of spectroscopy, atomic force microscopy (AFM), scanning electron microscopy (SEM) and X-ray Powder Diffraction (XRD), the role of ZnO NPs size on the antitumor activity of doxorubicin zinc oxide compositions is shown. AFM shows presence of many ZnO NPs on the surface DOX. A comparison of the FTIR spectra of DOX and its zinc oxide compositions has shown the presence of new bands of $\mathrm{OH}$ valence and deformation vibrations. It is possible to assume that interaction between $\mathrm{ZnO}$ and $\mathrm{DOX}$ takes place in the form of hydrogen bond, promoting the complexes formation. It is possible that both synergic and hydrogen-bonding $\mathrm{ZnO}$ with $\mathrm{DOX}$ increase the antitumor activity.

\section{INTRODUCTION}

The modification of known antitumor preparations for the purpose of reducing their system toxicity and side effects, as well as the development of new methods for target delivery of drugs are the most important tasks in oncology. The enhancement of selectivity in reaching target tissues as well as drug delivery efficiency is the major goal of oncology. Recently nanoparticles find application for transport of medicinal 
substances, in molecular diagnostics and as biological sensors or analyzers [1-4]. Nanoparticles can be divided into the following groups:

-nanoparticles containing organic and polymeric molecules as basic structural elements [5-10];

-nanoparticles containing inorganic substances, usually metals, metal oxides as basic elements [1114].

Ensembles of semi-conductor nanoparticles attached to a polymeric capsule can be used to transport medicinal agents in living organisms. As for the luminescent properties of semiconductor nanoparticles, they allow to trace the delivery process and make sure that necessary molecules have reached the destination place $[15,16]$. The important problems of the use of nanotherapeutic medicinal preparations are their side-effects; minimization of potential toxicity of nanoparticles; prevention of side effects related to the possible hematoencephalic barrier penetration, and many others. It is known that zinc oxide shows photocatalytic, antibacterial, antitumor activity under the influence of UV-radiation, while ZnO nanoparticles reveal such properties without UV irradiation [17, 18]. These results confirm our earlier investigations [19-21], where it was shown that decomposition of hydrogen peroxide on the surface of zinc oxide target accompanied by the formation of a $\mathrm{Zn}$-containing complex and was increased by two orders of magnitude when the target surface was photo activated by UV irradiation. When transforming to the gas phase, the complex decomposes on the surface of solid substrates with deposition of initial compound, ZnO. It is a chemical transport reaction (CTR), various modifications of which can receive wide acceptance in various areas of science and engineering. They are effective methods for transport of substances-just that determines their important role both in processes of formation of films, coatings and transport of drugs. Recent investigations on deposition of thin zinc oxide films on surface of salicylidene amino acid chelates with expressed antioxidant and antitumor properties by DC magnetron sputtering of a zinc target, have shown that zinc oxide composites in the form of coatings and composite films with polyvinyl alcohol (PVA) reveal higher (by 2 and 2.5 times) antitumor activity and considerable lower toxicity in comparison with the initial compounds $[22,23]$.

This paper is devoted to the systematization of data on antitumor activity of zinc oxide composites of doxorubicin [24-27], based on facile technology for obtaining them in the form of coatings, gels and composite films, alternative to the traditional nanotubes, nanoparticles. The novelty of this work in comparison with the previous research is the presentation of the role of nanoscale $\mathrm{ZnO}$ NPs sizes on antitumor activity of doxorubicin zinc oxide composites. $\mathrm{ZnO}$ nanoscale particles ( $\mathrm{ZnO} \mathrm{NPs}$ ) of a certain size are deposited directly on the drug surface in the form of coatings and composite films on glass substrate. Nanosize $\mathrm{ZnO}$ particles ( $\mathrm{ZnO} \mathrm{NPs}$ ) were deposited on the surfaces of DOX by DC-magnetron sputtering of zinc targets for the purpose of antitumor drug delivery to the tumour tissue in the form of coatings, composite films and gels taking into account antioxidant and transport properties of zinc oxide. Modification of antitumor drug (DOX) pursues the following objectives:

1) Formation of composite materials on the basis of DOX in the form of coatings, composite films and gels in the matrix of water soluble polymers.

2) Determination of optimum technological parameters of formation of DOX zinc oxide compositions with high antitumor activity and low toxicity by DC-magnetron modification of DOX surface.

3) Research of acute toxicity, drug (DOX) antitumor activity and their zinc oxide compositions.

It is expected that the achievement of the above-mentioned objectives will lead to the formation of zinc oxide compositions of antitumor drug doxorubicin with high antitumor activity and low toxicity.

\section{EXPERIMENTAL SECTION}

To obtain coatings, composite films from DOX and its zinc oxide composites commercial DOX preparation (lyophilized powder containing doxorubicin $(D O X)$ hydrochloride and mannitol in the ratio of 1:4, "Belmedpreparaty" Company, Belorussia) was used.

\subsection{Formation of Coating from DOX}

Coatings from lyophilized powder doxorubicin (DOX) hydrochloride were formed with dimethyl 
sulfoxide (DMSO) at room temperature, which was used as a solvent to obtain DOX in the form of paste. Coatings from the DOX paste for the further formation of their zinc oxide compositions at lower DOX doses $(2.5,3.0 \mathrm{mg} / \mathrm{kg})$ than the therapeutic dose for free DOX $(5.0 \mathrm{mg} / \mathrm{kg})$ were obtained on various glass substrates representing circles of different diameters. These low DOX doses in the zinc oxide composites were chosen assuming the vector character of transport of the zinc oxide composites to tumor tissues. The formation process of DOX zinc oxide compositions is related to their physical and chemical properties as well as their surface area which determine $\mathrm{Zn}$ amount and size of $\mathrm{ZnO}$ nanoparticles deposited on its surface.

\subsubsection{Formation of Hydrogels from DOX}

DOX with DMSO in the form of paste is applied on glass substrates of certain area depending on the selected dose of antitumor preparation. After formation of DOX paste the substrates with DOX coating are placed in DC-magnetron to deposit nanosize zinc oxide NPs on their surfaces. The ZnO NPs is determined by optimum technological parameters of its formation on the coating surface. The zinc oxide composite of DOX (DOX $+\mathrm{ZnO})$ obtained by deposition of $\mathrm{ZnO}$ NPs on the surface of glass substrates coated with DOX, was dissolved by sonication $(20 \mathrm{~Hz}, 60 \mathrm{sec}, 65 \%$ amplitude) in physiological salt solution, where the following polymer/polymer mixture was dissolved: starch-sodium carboxymethyl cellulose (Starch + Na-CMC-0.3\%), 2-hydoxyethyl cellulose (HEC-0.3\%), polyethylene oxide (PEO—0.3\%).

\subsubsection{Formation of Composite Films from DOX}

A series of composite films from DOX was obtained. The DOX was mixed with preliminary prepared polyvinyl alcohol (PVA) solution, and films of a certain diameter were formed on glass substrates from the obtained solutions.

Combined DOX-PVA films were formed by spin-coating method. Further, glass substrates with films were placed in the magnetron, and using DC-magnetron sputtering of $\mathrm{Zn}$ targets nanosize $\mathrm{ZnO}$ layers were deposited on the film surface. The ZnO NPs was controlled by optimum technological parameters of the deposition process. PVA $+\mathrm{DOX}+\mathrm{ZnO}$ were transferred in water emulsion by ultrasonic dispersion. Several samples of PVA and modified polyvinyl alcohol (MPVA) differed in molecular mass (MM) and functional composition were used to create the required polymeric matrix and choose the conditions of obtaining the films prospectively appropriate for their combination with $\mathrm{DOX}$ and $\mathrm{ZnO}$. The basic characteristics of PVA and MPVA samples are shown in Table 1.

\subsection{The DC-Magnetron Deposition of the Nanoscale ZnO Particle on the Surfaces of DOX, DOX + PVA}

DC-magnetron deposition of ZnO NPs on the surface of DOX in the form of coatings and DOX + PVA, composite films was carried out using UVN-71-P3 modified device equipped with a measurement system and $\mathrm{Ar}: \mathrm{O}_{2}$ gases flow control regulators. The high purity metal ( $\mathrm{Zn}$ of $99.99 \%$ purity) for deposition of $\mathrm{ZnO} N$ ss on the surface of antitumor preparations at $10^{-3} \mathrm{~mm} \mathrm{Hg}$ vacuum ensures obtaining the zinc oxide compositions of high purity antitumor preparations. The measurement and control system (power

Table 1. The basic characteristics of PVA samples.

\begin{tabular}{|c|c|c|c|c|}
\hline \multirow[t]{2}{*}{ PVA samples } & \multirow[t]{2}{*}{$\mathrm{MM} / 10^{3}$} & \multicolumn{3}{|c|}{ Functional groups, w.\% } \\
\hline & & $\begin{array}{l}\text { Hydroxyl groups, } \\
\text { weight } \%\end{array}$ & $\begin{array}{c}\text { Acetate groups, weight \% } \\
-\mathrm{OCOCH}_{3}\end{array}$ & $\begin{array}{c}\text { Total salt-COONa, } \\
\text { weight } \%\end{array}$ \\
\hline PVA-1 & 20 & 98.5 & 1.5 & - \\
\hline PVA-2 & 20 & 88.4 & 10.6 & - \\
\hline PVA-5 & 65 & 98.4 & 1.6 & - \\
\hline MPVA-14 & 62 & 83.1 & 13.5 & 2.8 \\
\hline
\end{tabular}


and indication unit PR4000F) as well as the working gases control system ( $\mathrm{Ar}$ and $\mathrm{O}_{2}$ gases flow regulators MFC1179) ensure very accurate measurement and control (within the accuracy of $\pm 1 \%$ ) of the content and vacuum level in the chamber during the whole film formation process, at the same time providing stability of the process parameters and, hence, reproducibility of the properties of zinc oxide compositions to be obtained. When selecting technological regimes of nanoscale $\mathrm{ZnO}$ particle deposition (the working gases $\mathrm{Ar}: \mathrm{O}_{2}$ ratio, magnetron current, target-to-substrate distance, substrate temperature on the surface of antitumor preparations within $-30^{\circ} \mathrm{C} \leq \mathrm{T} \leq 30^{\circ} \mathrm{C}$ temperature range) it is important to take into account the conditions preventing undesirable side transformations of drugs. Measurement and control of $\mathrm{ZnO}$ film thickness was carried out by "Micron-7" automatic control system. ZnO NPs of a certain size were deposited on the surface of medicinal preparations with an accuracy of $\pm 0.1 \mathrm{~nm}$.

\subsection{Characterization of DOX and Zinc Oxide Composites}

X-ray diffraction (XRD) patterns were obtained on Empyrean X-ray diffractometer, PANalytical Company. IR spectra were recorded on NEXUS FT-IR spectrometer. UV spectra were recorded on TF-C-UVIS-SR 220 - $1100 \mathrm{~nm}$, Stellar Net Inc.com spectrophotometer. AFM images were recorded on Solver Nano II, MT NDT and SEM on TESCAN 3115 microscope. ZnO amount was determined by atomic absorption spectroscopy of $\mathrm{Zn}$ analysis in $\mathrm{ZnO}$ composites of $\mathrm{DOX}$ in the form of coating and composite films (AAS1 spectroscope).

\subsection{An Investigation Method of Antitumor Activity and Toxicity of Doxorubicin and Its Zinc Oxide Compositions}

The study was carried out in Toxicology and Chemotherapy Laboratory of Scientific Technological Centre of Organic and Pharmaceutical Chemistry of the National Academy of Sciences of the Republic of Armenia under conditions close to GLP principles and European standards.

Acute toxicity studies were conducted on outbred mice. Six animals (white nondescript mice, 6 - 7 weeks old with an average weight of 20 to $25 \mathrm{~g}$ ) were used for each experimental group. Maximum tolerant doses (MTD) and lethal (LD) doses were found out. On the basis of the obtained results, therapeutic doses were calculated that usually were made up $1 / 5$ of a single MTD. For the in vivo experiments, antitumor properties were studied on the model of mice transplantable tumors: Ehrlich ascitic carcinoma (EAC). The tumor transplantation is carried out by intraperitoneal injection of ascetic liquid to the animals. Zinc oxide compositions of doxorubicin in physiological solution were introduced into mice by intraperitoneal injections. Evaluation of antitumor activity in EAC-by the animal's lifespan increase (ILS).

At the end of the experiment, animals were passed to histological studies. For histological evaluation of changes of the liver, kidney and spleen the animals were euthanized and samples of mentioned organs from each group were collected and stored in $10 \%$ buffered formalin. After dehydration samples were embedded in paraffin, 3 - $5 \mu \mathrm{m}$ sections were prepared and stained with H\&E. Histopathological observations were made at $250 \times$ magnification using a light microscope (Jenaval).

\section{RESULTS AND DISCUSSION}

\subsection{Obtaining Medicinal Preparations in the Form of DOX + ZnO Coating and Studying Their Antitumor Activity}

Optimum surface areas of DOX on glass substrates were calculated taking into account the results earlier obtained for $\mathrm{Cu}$ (II) chelates of salicylidene amino acids [22, 23]. $\mathrm{ZnO}$ content in the film, which made $5 \%-10 \%$ of that of DOX weight, was taken for rough estimate with a view to obtain reliable optimum results to ensure technological effectiveness of the deposition process. The surface area of DOX coating was calculated for the dose of DOX for introduction into 6 mice on the basis of a simplified assumption that the content of this dose (in $\mathrm{mg}$ ) was inside a sphere of a certain volume $\left(\mathrm{cm}^{3}\right)$. The formation of DOX zinc oxide composites and study of antitumor activity were carried out using significantly 
lower doses of DOX than the therapeutic dose for free DOX for the purpose of increasing antitumor activity and decreasing toxicity. On the model of EAC, the dependence of antitumor activity of doxorubicin zinc oxide composites on size of $\mathrm{ZnO}$ NPs was studied for $2.5,3.0 \mathrm{mg} / \mathrm{kg}$ doses and $5.0 \mathrm{mg} / \mathrm{kg}$ therapeutic dose for free DOX (Table 2). So, for $2.5 \mathrm{mg} / \mathrm{kg}$ dose surface area of the preparation made up $1.57 \mathrm{~cm}^{2}$ (circle diameter was $1.41 \mathrm{~cm}$ ) and $1.33 \mathrm{~cm}^{2}$ for $3 \mathrm{mg} / \mathrm{kg}$ dose of DOX. The dependence of antitumor activity of the zinc oxide composites on the size of $\mathrm{ZnO}$ areas of DOX coatings was studied at $2.5,3.0 \mathrm{mg} / \mathrm{kg}$ doses and different $\mathrm{ZnO}$ film thickness on glass substrate $\mathrm{d}=70-250 \mathrm{~nm}, \mathrm{t}=10,20,30,40 \mathrm{~min}$ ) and $\mathrm{ZnO} \mathrm{NPs}$ on DOX and DOX + PVA surface.

Table 2 shows data on antitumor activity of zinc oxide composites for several doses and various thickness of $\mathrm{ZnO}$ films on glass substrate and $\mathrm{ZnO}$ NPs on DOX and DOX + PVA coated glass substrates. $\mathrm{ZnO}$ content is from $5 \%$ to $10 \%$ of the amount of DOX. The dependence of antitumor activity of DOX zinc oxide composites on the deposition time and $\mathrm{ZnO}$ NPs covering a certain area of the DOX surface was determined (Table 2). The dependence of antitumor activity zinc oxide composites on DOX coating area was determined at fixed time and thickness of deposited nanosize $\mathrm{ZnO}$ films on glass substrate, and $\mathrm{ZnO}$ NPs on DOX coated glass substrate at fixed surface area (diameters). The results of investigations of doxorubicin zinc oxide composites the DOX revealed the increase in antitumor activity $(332.3 \%)$ in comparison with DOX at optimal $5.0 \mathrm{mg} / \mathrm{kg}$ therapeutic dose (170\%) and much higher increase (two fold) in comparison with DOX at the same dose (165\%) (Table 2). ZnO NPs size on DOX surface in the average is made up $90 \mathrm{~nm}$ and $\mathrm{ZnO}$ film thickness on glass surface $-180 \mathrm{~nm}$. The growth rate of $\mathrm{ZnO}$ film on the glass substrate in average is $6.44 \mathrm{~nm} / \mathrm{min}$, and $\mathrm{ZnO}$ NPs on the surface DOX $-3.5 \mathrm{~nm} / \mathrm{min}$ (see Table 2).

\subsubsection{Obtaining Medicinal Preparations in the form of Polymer + DOX + ZnO Gels and Studying Their Antitumor Activity}

The gels based on the starch-sodium carboxymethylcellulose (Starch + Na-CMC) system containing the zinc oxide composite of DOX were investigated. Total concentration of polymers (1:1 by weight) in gel samples made $0.3 \%$ the amount of DOX was taken on the basis of $3.0 \mathrm{mg} / \mathrm{kg}$ dose. $\mathrm{ZnO}$ NPs deposition time was $3.0 \mathrm{~min}$ for all the obtained samples of coatings, and at the given technological parameters of $\mathrm{Zn}$ target magnetron sputtering, the film thickness was $180 \mathrm{~nm}$ on glass substrate for gel samples with the polymer concentration of $0.3 \%$. Study of antitumor properties of the obtained gels carried out on the mice with inoculated ascitic Ehrlich's carcinoma after a single intraperitoneal introduction of about $0.3 \mathrm{ml}$ of the antitumor complex, has revealed high antitumor activity together with low toxicity for the gels in comparison with control mice (168.9\%) for DOX therapeutic dose of $5.0 \mathrm{mg} / \mathrm{kg}$. The antitumor activity was determined from the life span increase (ILS) in comparison with the control animals. It is seen from Table 2 that the maximum antitumor activity (332.6\%) of HEC $+\mathrm{DOX}+\mathrm{ZnO}$ is also observed for $180 \mathrm{~nm}$ thickness of $\mathrm{ZnO}$ film on glass substrate, and within the average $90 \mathrm{~nm}$ on the initial coating. Polymer concentration of $0.3 \%$ and $180 \mathrm{~nm}$ thick $\mathrm{ZnO}$ film on glass substrate and within the average $90 \mathrm{~nm} \mathrm{ZnO}$ NPs on DOX surface the antitumor activity amounted $384.1 \%$. High antitumor activity was also observed in the case of PEO based gels (334.9\%) within the average $90 \mathrm{~nm} \mathrm{ZnO} \mathrm{NPs} \mathrm{on} \mathrm{the} \mathrm{DOX.}$

\subsubsection{Obtaining Medicinal Preparations in the form of PVA + DOX + ZnO Films and Studying their Antitumor Activity}

The PVA samples were: PVA-1 and PVA-2 MM $\approx 20,000$, mass fraction of acetate group $10.6 \%$ and $1.5 \%$, PVA-5, $M M \approx 65,000$ and mass fraction of acetate group-1.6\%. MPVA-14, $M M \approx 62,000$ and mass fraction of acetate group-13.5\% (Table 1). PVA-5 differs from PVA-1 and PVA-2 by higher MM with the same as in PVA-1 mass fraction of acetate group. Solubility of the films before and after deposition of $\mathrm{ZnO}$ NPs was studied both in model conditions at various $\mathrm{pH}$ and in vivo by intraperitoneal introduction to mice and measurement of solubility time. PVA-5 was selected as a composite film base; its molecular mass (6500) is higher than PVA-1and PVA-2, however the acetate group content (1.6\%) is approximately the same as in PVA-1. PVA-5 + DOX + ZnO samples have shown high ILS at dose of $2.5 \mathrm{mg} / \mathrm{kg}(304.3 \%)$ and at dose of $3.0 \mathrm{mg} / \mathrm{kg}(390 \%)$ in comparison with DOX control samples at dose of $5.0 \mathrm{mg} / \mathrm{kg}(176 \%)$ 
Table 2. Antitumor activity of doxorubicin and its zinc oxide compositions in the form of coating, gels and combined films on the model of ascitic Ehrlich's carcinoma.

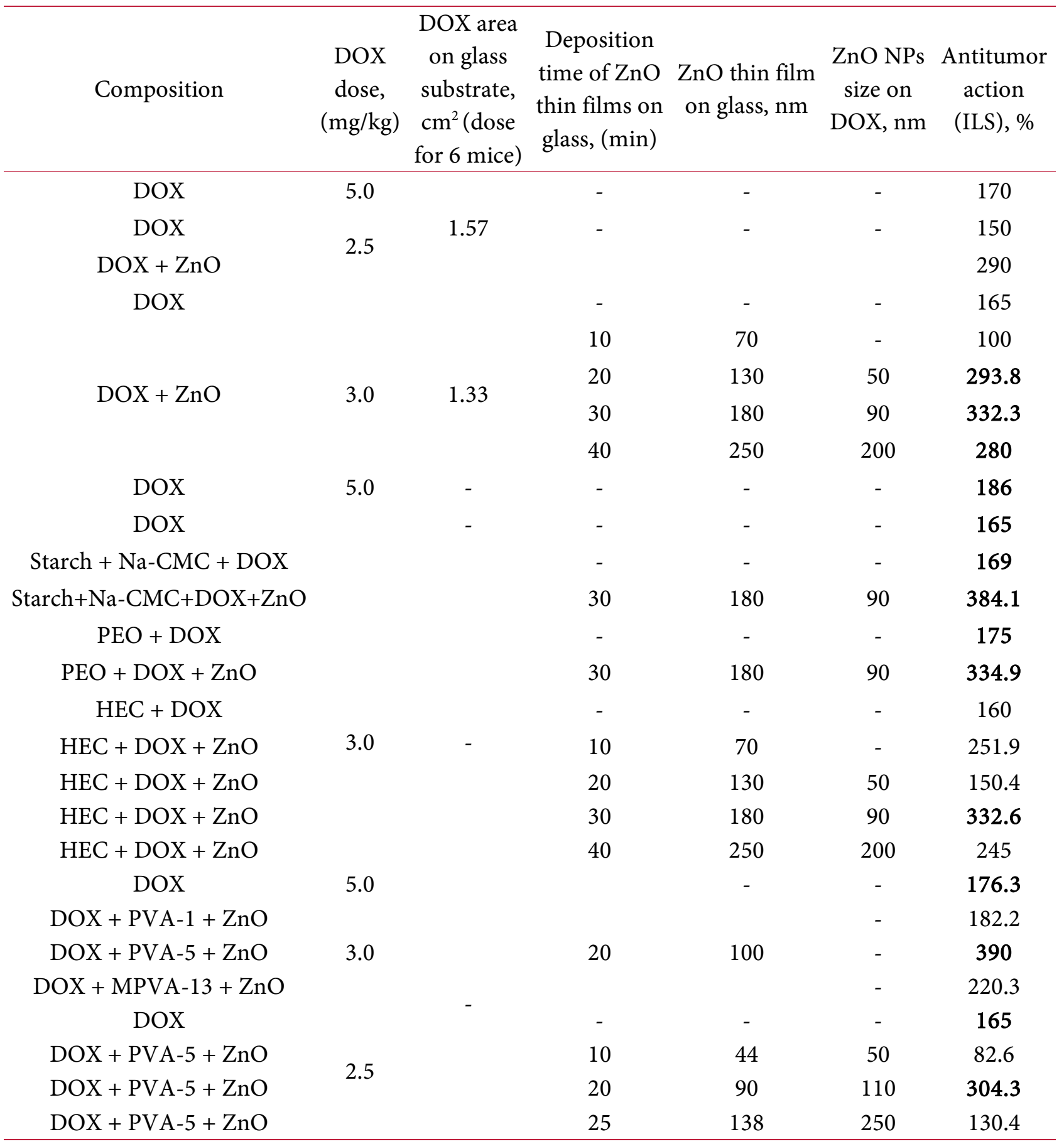

(Table 2). ZnO NPs size made $110 \mathrm{~nm}$ on DOX + PVA-5 surface and $\mathrm{ZnO}$ film thickness on glass surface- $-90 \mathrm{~nm}$.

\subsection{Optimum Parameters of DC Magnetron Deposition of ZnO and Structural Characteristics of Zinc Oxide Compositions of DOX}

The nature of the $\mathrm{ZnO}$ thin films deposition on glass substrates was investigated for the purpose of 
obtaining optimal technological parameters for preparations of crystalline $\mathrm{ZnO}$ films on glass substrate for further deposition of ZnO NPs on DOX, DOX + PVA surfaces for preparing DOX zinc oxide composites. $\mathrm{X}$-ray investigations of nanosize $\mathrm{ZnO}$ film (Empyrean $(\lambda \mathrm{CuK} \alpha)$ has shown that the structure depends on power of the magnetron source. By the technique of DC-magnetron sputtering of zinc target we produced polycrystalline samples of $\mathrm{ZnO}$ films oriented along the crystallographic direction (002) on glass substrates (see Figure 1). Optimum target-to-substrate distance was $13 \mathrm{~cm}$, and ratio of working gases $A r: \mathrm{O}_{2}=3: 1$, with power of magnetron source $120 \mathrm{~W}$ was selected taking into account the obtained dependences and uniformity of the $\mathrm{ZnO}$ films deposited on glass substrate. At such target-to-substrate distance the film growth rate made $6.5-7 \mathrm{~nm} / \mathrm{min}$ on glass substrate.

Zinc oxide composites of doxorubicin were obtained by DC-magnetron deposition of ZnO NPs (using a $\mathrm{Zn}$ target) on doxorubicin surfaces in the form of coatings or composite films in the optimal technological mode obtained on glass substrates: operating current was $400 \mathrm{~mA}$, gas mixture $\mathrm{Ar}: \mathrm{O}_{2}$ at 70:30 ratio; operating pressure $10^{-3} \mathrm{~mm} \mathrm{Hg}$, target-to-substrate distance $13 \mathrm{~cm}$. Figure 1 shows diffractograms of DOX, DOX + DMSO and doxorubicin zinc oxide composite samples obtained at different times of deposition of $\mathrm{ZnO}$ NPs on the surfaces of doxorubicin coatings. The diffractogram of DOX + DMSO (Figure 1) clearly shows intense peaks of interplanar distances and AFM pictures (Figure 3(a), Figure 3(k)) indicating the orientation of DOX micro particles. In $\mathrm{DOX}+\mathrm{ZnO}, \mathrm{DOX}+\mathrm{PVA}+\mathrm{ZnO}, \mathrm{ZnO} \mathrm{NPs}$ are oriented along 002 crystallographic direction in the same manner as on glass substrates (Figure 1, Figure 2) to reveal the character of $\mathrm{DOX}+\mathrm{ZnO}, \mathrm{DOX}+\mathrm{PVA}+\mathrm{ZnO}$ interaction, crystalline characteristics of $\mathrm{DOX}$ and DOX zinc oxide composites were investigated at $180 \mathrm{~nm} \mathrm{ZnO}$ film thickness deposition on the glass substrate and different $\mathrm{ZnO}$ NPs (within the average of 50, 90 and $200 \mathrm{~nm}$ ) on surface of DOX coatings (Figure 1, Table 2) and within the average of 50, 110 and $250 \mathrm{~nm}$ composite films on DOX + PVA surface (Figure 2, Table 2). An increase in antitumor activity was observed for doxorubicin zinc oxide composites, 332.3\%, in the form of coatings, when deposition of ZnO NPs with $90 \mathrm{~nm}$ average sizes on DOX surface was carried out at lower $3.0 \mathrm{mg} / \mathrm{kg}$ doxorubicin doses than the therapeutic dose $(5 \mathrm{mg} / \mathrm{kg})$, at which DOX activity made up $170 \%$. Significant increase of antitumor activity and decrease of toxicity on the model of ascitic Ehrlich's carcinoma was shown for doxorubicin zinc oxide composites at lower 2.5, 3 $\mathrm{mg} / \mathrm{kg}$ doxorubicin doses than therapeutic one $(5 \mathrm{mg} / \mathrm{kg}$ ) for coating and $3 \mathrm{mg} / \mathrm{kg}$ for gels in the case of deposition within $90 \mathrm{~nm}$ the average size of ZnO NPs. In the case of ZnO NPs of $200 \mathrm{~nm}$ size an excess amount of $\mathrm{Zn}$ resulted in a slight decrease of antitumor activity of the composites (see Table 2). Thus, in zinc oxide composites of doxorubicin the regulation of $\mathrm{ZnO}$ NPs sizes plays an important role in target delivery of antitumor medicinal preparations into the tumor tissue determining high antitumor activity and low toxicity in the case of deposition within the average of $50-200 \mathrm{~nm}$ sizes of ZnO NPs on doxorubicin surface and within the average of $110 \mathrm{~nm}$ NPs size for DOX + PVA + ZnO (Table 2).

Figure 3(a), Figure 3(d) show AFM 2D and 3D microphotographs of DOX on glass substrate, Figure 3(b), Figure 3(e)—nanosize (180 nm thick) $\mathrm{ZnO}$ film on glass substrate, and Figure 3(c), Figure 3(f)$\mathrm{DOX}+\mathrm{ZnO} \mathrm{NPs}$ (within the average $90 \mathrm{~nm}$ ) coating. The AFM microphotographs show many nanosize $\mathrm{ZnO} N \mathrm{~N}$ s formations on DOX surface obtained at the same (optimum) technological parameters of deposition as $\mathrm{ZnO}$ films on glass. It is seen from Figure 3(a) (AFM) and Figure 3(k) (SEM) that the surface of DOX consists of $0.5-6 \mu \mathrm{m}$ long extended particles of non regular cylindrical form of $0.5-0.8 \mu \mathrm{m}$ in diameter, and Figure 3(c), Figure 3(f) represent $\mathrm{ZnO}$ NPs of average $90 \mathrm{~nm}$ size formations on the DOX micro particles. At the same deposition time $(30 \mathrm{~min})$ the thickness of $\mathrm{ZnO}$ film is $180 \mathrm{~nm}$ on the glass surface (Table 2). Figure 3(g), Figure 3(i) and Figure 3(l) and Figure 3(m) show AFM and SEM microphotographs of DOX + PVA and DOX + PVA + ZnO. It is seen from Figure $3(\mathrm{~g})$ that the surface of DOX + PVA consists of $250-700 \mathrm{~nm}$ in cross section and DOX + PVA + ZnO show particle with $110 \mathrm{~nm}$ average width.

As it is known from the publications, at UV irradiation or plasma treatment of $\mathrm{ZnO}$ films the electrons can interact with the $\mathrm{Zn}$ lattice ions forming $\mathrm{Zn}^{+}$defect regions [28], what in our opinion is favourable to the adsorption of the doxorubicin hydroxyl groups and leads to the formation of a charge transfer doxorubicin complex. Plasma is a good source of ultraviolet irradiation, so plasma treatment could be 


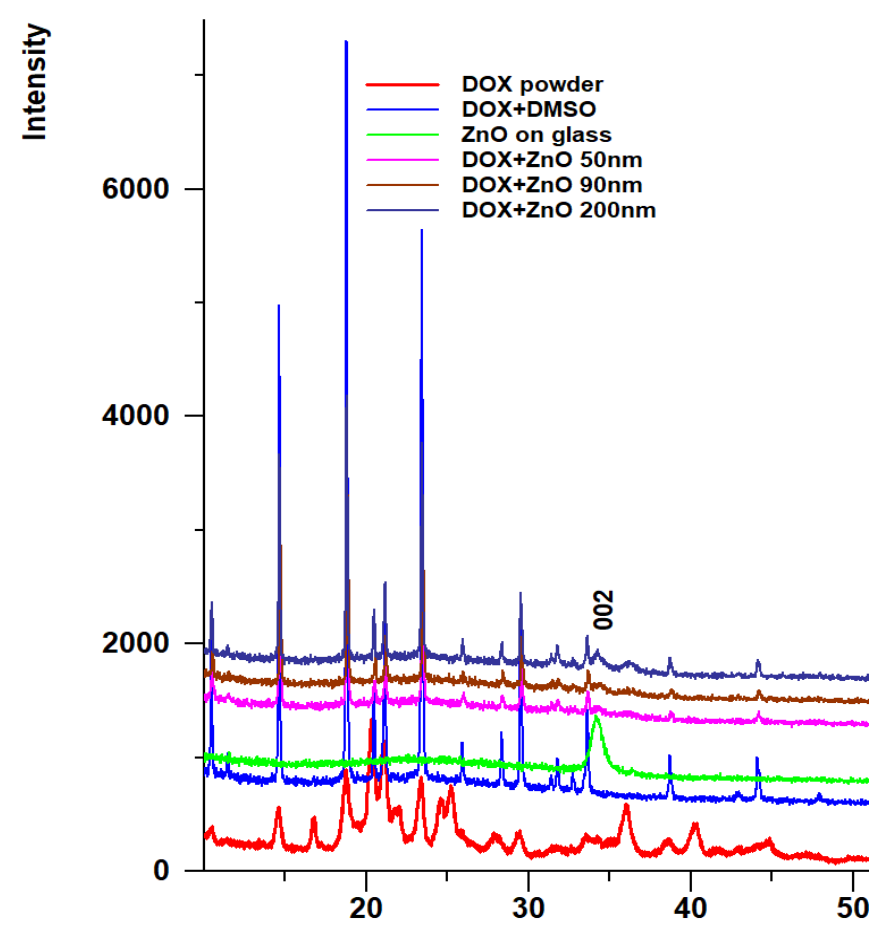

Figure 1. X-ray diffraction pattern of DOX, DOX + DMSO and their zinc oxide composites at $\mathrm{ZnO}$ NPs size $50,90,200 \mathrm{~nm}$.

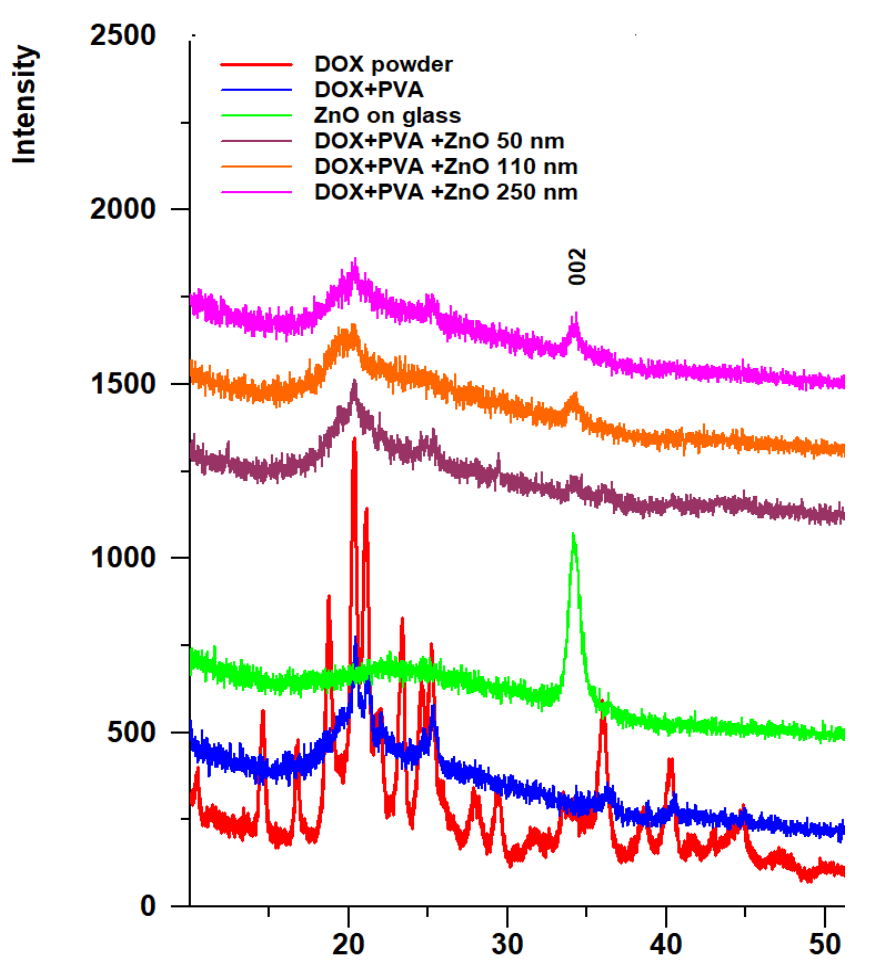

Figure 2. X-ray diffraction pattern of DOX, DOX + PVA and their zinc oxide composites at $\mathrm{ZnO}$ NPs size 50, 110, $250 \mathrm{~nm}$. 


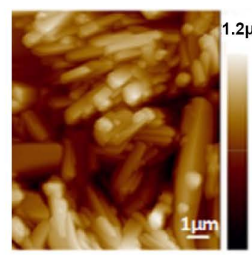

2D: a - DOX

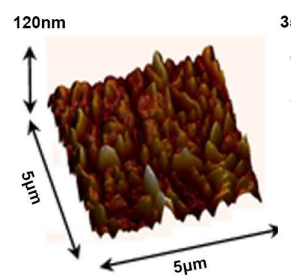

3D: g-DOX + PVA

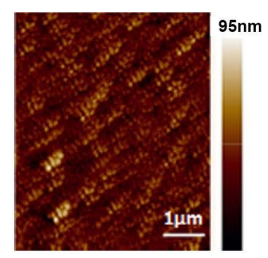

$\mathrm{b}-\mathrm{ZnO}$ on glass

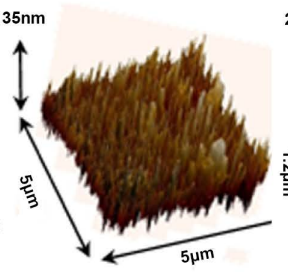

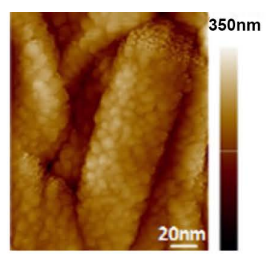

c - DOX-ZnO

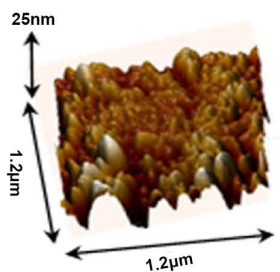

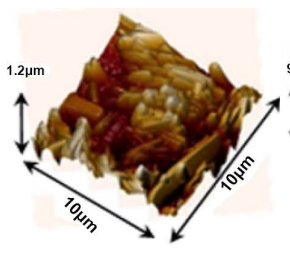

3D: d - DOX

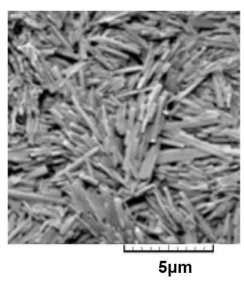

$\mathrm{k}-\mathrm{DOX}$

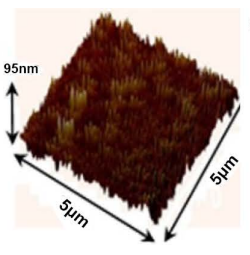

e - $\mathrm{ZnO}$ on glass

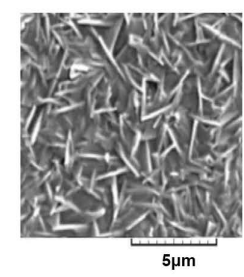

$\mathrm{f}-\mathrm{DOX}+\mathrm{ZnO}$

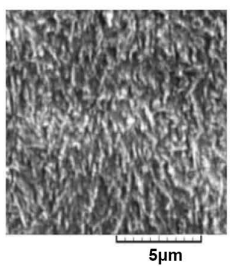

1 - DOX + PVA $\mathrm{m}-\mathrm{DOX}+\mathrm{PVA}+\mathrm{ZnO}$

Figure 3. AFM pictures: (a)-(i)—-morphology samples DOX, ZnO (90, $180 \mathrm{~nm}), \mathrm{DOX}+\mathrm{ZnO}, \mathrm{DOX}+$ PVA + ZnO; SEM picture: (k,) (l), (m)-morphology samples DOX, DOX + PVA, DOX + PVA + ZnO.

considered as an analogue of UV irradiation, and the generation of electron-hole pairs on the $\mathrm{ZnO}$-antitumor drug interface could promote the formation of charge transfer complexes. During the deposition and formation of nanosize zinc oxide films on the surface of doxorubicin, electron-hole pairs were apparently generated in plasma. Thus, in zinc oxide composites of doxorubicin the regulation of ZnO NPs size and the complex cation balance apparently affects their toxicity and antitumor toxicity. Vector character of the transport of zinc oxide compositions of antitumor medicinal preparations into the tumor tissue determines increase in their activity and decrease in toxicity, which is apparently related to the choice of optimum process parameters of DC-magnetron deposition, in particular, to the ZnO NPs size on the surface of antitumor drugs to form complex antitumor drugs with zinc oxide.

FTIR spectra of doxorubicin (lyophilized powder containing DOX and mannitol in the ratio of 1:4, "Belmedpreparaty" Company, Belorussia) and zinc oxide composites of doxorubicin ( $\mathrm{DOX}+\mathrm{ZnO}$ ) were recorded in nujol oil. Both spectra contain the following characteristic absorption bands: $3387,3285 \mathrm{~cm}^{-1}$ (valence vibrations of $\mathrm{OH}), 1720,1616 \mathrm{~cm}^{-1}(\mathrm{C}=\mathrm{O}), 1565 \mathrm{~cm}^{-1}$ (aromatic ring), 1281, 1264, 1209, 1082, $1018 \mathrm{~cm}^{-1}$ (deformation vibrations of $\mathrm{OH}$ ), 701,631,584 $\mathrm{cm}^{-1}(1,2,3$ substituted aromatic ring). Comparison of (DOX) and $\mathrm{DOX}+\mathrm{ZnO}$ absorption spectra has shown the presence of new bands of $\mathrm{OH}$ valence and deformation vibrations at 3325 and $1043 \mathrm{~cm}^{-1}$, correspondingly, as well as $\mathrm{ZnO}$ absorption band at $418 \mathrm{~cm}^{-1}$. Taking into account the obtained data, it is possible to come to the conclusion on interaction between $\mathrm{ZnO}$ and DOX, presumably, in the form of hydrogen bond promoting the complexes formation.

\subsection{Comparative Histological Studies of Mice Organs after Treatment with DOX and DOX + ZnO}

It is known that doxorubicin causes significant damaging action on some internal organs of experimental animals [29]. In this connection, histological studies of the liver, kidneys and spleen were carried out. It was established that under the influence of both doxorubicin in a dose of $3.0 \mathrm{mg} / \mathrm{kg}$ and its zinc oxide composites in the form of coatings with DOX content in a dose of $3 \mathrm{mg} / \mathrm{kg}$, various pathological abnormalities are observed in all the organs.

In the macroscopic studies it has been found out that compared to control animals in the experimental mice kidneys were anemic and reduced in size. The liver was enlarged in size, had pale surface. In mice treated with DOX in the mucosa of stomach and intestines multiple hemorrhages and erosions more often were revealed more often, than in mice treated with $\mathrm{DOX}+\mathrm{ZnO}$.

Microscopic studies have shown that in mice treated with DOX some histological structure abnormalities were observed in liver, kidneys and spleen. The whole liver parenchyma has revealed fatty degeneration, 


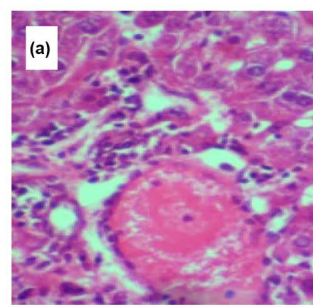

Liver-DOX

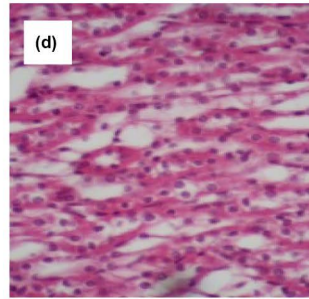

Kidney -DOX

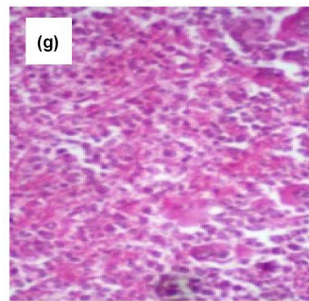

Spleen-DOX
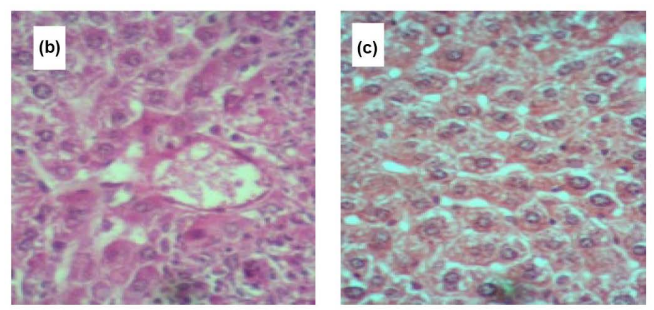

Liver-DOX $+\mathrm{ZnO}$
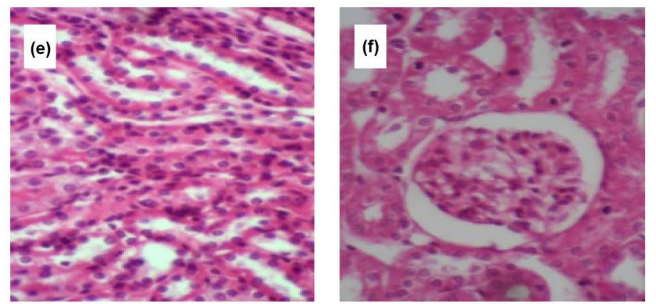

Kidney-DOX $+\mathrm{ZnO}$
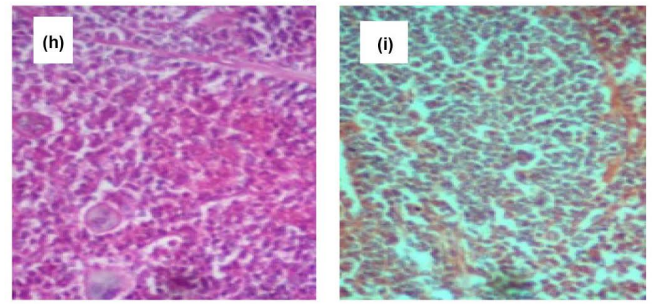

Spleen-DOX $+\mathrm{ZnO}$

Figure 4. Microscopic pictures (H\&E staining) of mice organs after treatment with $\mathrm{DOX}$ and $\mathrm{DOX}+\mathrm{ZnO}$.

the girder structure is abnormal, and in the parenchyma there are small nidi of necrosis as well as signs of karyolysis and karyopyknosis are noted. Lymphohistiocytic infiltration is observed in the liver portal tract (Figure 4(a)). These abnormalities occur to a lesser degree under the action of DOX + ZnO lipophanerosis mainly is noted in the peripheral parts of the liver lobules (Figure 4(b), Figure 4(c)). Under the action of DOX histological structure of kidneys is mostly damaged. Dystrophic changes of the convoluted tubules are noted, where nuclei are not often present. In nephrocytes plasmolysis phenomena is recorded. Sometimes infiltration processes in the kidney cortex, as well as a diffuse lesion of renal glomerules are observed. In the proximal and distal tubules of the renal parenchyma phenomena of fatty dystrophy are defined. Tubular lumen is narrowed (Figure $4(\mathrm{~d})$ ). These pathologies are qualitatively reduced under the $\mathrm{DOX}+\mathrm{ZnO}$ action, although in this case there is plethora in the blood capillaries of the medullary substance with the phenomena of perivascular infiltration. (Figure 4(e), Figure 4(f)) histological structure of spleen under the DOX $+\mathrm{ZnO}$ action is relatively better preserved (Figure 4(h), Figure 4(i)). In spleen under DOX action hyperplastic processes, nodi of leukemic and diffusive infiltrations and partial destruction of the follicles are found. In the pulp and sinuses outbreaks of destructive changes of the red pulp, as well as regions of infiltrations of the lymphoid character in the sinuses are recorded (Figure 4(g)). Along with the abovementioned changes, histological structure of spleen under the $\mathrm{DOX}+\mathrm{ZnO}$ action is relatively better preserved (Figure 4(h), Figure 4(i)). The morpho-histological data obtained demonstrate that when using zinc oxide compositions of doxorubicin, some decrease of its damaging action on some internal organs of animals takes place.

\section{CONCLUSIONS}

In summary, we have reported the doxorubicin modification by DC-magnetron deposition of $\mathrm{ZnO}$ 
NPs on the drug surface resulting in the formation of zinc oxide compositions in the form of coatings, polymer based films and gels. The effect of the size of modified surface, size of nanoscale $\mathrm{ZnO}$ particles deposited on it, as well as compositions with the polymers of various molecular weights, concentration and a certain functional composition, ensuring prolonged action in animal (mice) organisms, on the antitumor activity and toxicity of the obtained zinc oxide compositions were studied. An increase in antitumor activity and decrease in toxicity of doxorubicin zinc oxide composites in the form of coating $(\mathrm{DOX}+\mathrm{ZnO})$ at optimally chosen coated areas were revealed in the range of $50-200 \mathrm{~nm} \mathrm{ZnO}$ NPs, hydrogels with $\mathrm{ZnO}$ NPs in the range of $90-200 \mathrm{~nm}$ and composite films (DOX + PVA $+\mathrm{ZnO}$ ) with an optimum polymeric matrix for $\mathrm{ZnO}$ NPs of $110 \mathrm{~nm}$ size.

Chemotherapeutic investigations on the model of Erlich's carcinoma have revealed significant increase in antitumor activity regarding life span increase (ILS, \%) together with decrease in toxicity of the doxorubicin zinc oxide compositions at the drug dose of $3 \mathrm{mg} / \mathrm{kg}$ in the form of coatings (332\%), composite films with PVA (390\%) as well as Starch + Na-CMC (384\%), HEC (330\%) and PEO (332.6\%) based hydrogels in comparison with therapeutic $5 \mathrm{mg} / \mathrm{kg}$ dose of DOX (170\%). Vector character of the transport of zinc oxide compositions of medical preparations into the tumor tissue determines increase in their activity and decrease in toxicity, which is apparently related to the choice of optimum process parameters of DC-magnetron deposition, in particular, to the $\mathrm{ZnO}$ NPs size on the surface of antitumor drug in the form of coatings, composite films, hydrogels to form complex antitumor drugs with zinc oxide.

\section{FUND}

This work was supported by Grant A-1962 awarded by the International Science and Technology Center.

\section{CONFLICTS OF INTEREST}

The authors declare no conflicts of interest regarding the publication of this paper.

\section{REFERENCES}

1. Zhao, C.Y., Cheng, R., Yang, Z. and Tian, Z.M. (2018) Nanotechnology for Cancer Therapy Based on Chemotherapy. Molecules, 23, E826. https://doi.org/10.3390/molecules23040826

2. Xin, Y.R., Yin, M.M., Zhao, L.Y., Meng, F.L. and Luo, L. (2017) Recent Progress on Nanoparticle-Based Drug Delivery Systems for Cancer Therapy. Cancer Biology \& Medicine, 14, 228-241.

3. Mousavi, S.M., Hashemi, S.A., Zarei, M., Amani, A.M. and Babapoor, A. (2018) Nanosensors for Chemical and Biological and Medical Applications. Med Chem (Los Angeles), 8, 8.

https://doi.org/10.4172/2161-0444.1000515

4. Patra, J.K., Das, G., Fraceto, L.F., Campos, E.V.R., del Pilar Rodriguez-Torres, M., Acosta-Torres, L.S., Diaz-Torres, L.A., Grillo, R., Swamy, M.K., Sharma, S., Habtemariam, S. and Shin, H.-S. (2018) Nano Based Drug Delivery Systems: Recent Developments and Future Prospects. Journal of Nanobiotechnology, 16, 1-33.

https://doi.org/10.1186/s12951-018-0392-8

5. Pandey, S.K. (2016) Controlled Release of Drug and Better Bioavailability Using Poly (Lactic Acid-Co-Glycolic Acid) Nanoparticles. International Journal of Biological Macromolecules, 89, 99-110.

https://doi.org/10.1016/j.ijbiomac.2016.04.065

6. Kumari, P. (2017) Cholesterol-Conjugated Poly (D, L-lactide)-Based Micelles as a Nanocarrier System for Effective Delivery of Curcumin in Cancer Therapy. Drug Delivery, 24, 209-223.

https://doi.org/10.1080/10717544.2016.1245365

7. Yallapu, M., Gupta, B., Jaggi, M. and Chauhan, S. (2010) Fabrication of Curcumin Encapsulated PLGA Nanoparticles for Improved Therapeutic Effects in Metastatic Cancer Cells. Journal of Colloid and Interface Science, 
351, 19-29. https://doi.org/10.1016/j.jcis.2010.05.022

8. Chan, J.M., Valencia, P.M., Zhang, L., Langer, R. and Farokhzad, O.C. (2010) Polymeric Nanoparticles for Drug Delivery. Methods in Molecular Biology, 624, 163-175. https://doi.org/10.1007/978-1-60761-609-2_11

9. Pieper, S., Onafuye, H., Mulac, D., Cinatl Jr., J., Wass, M.N., Michaelis, M. and Langer, K. (2018) Incorporation of Doxorubicin in Different Polymer Nanoparticles and Their Anti-Cancer Activity BioRxiv Preprint First Posted Online.

10. Du, Y.L., Xia, L., Jo, A., Richey, M.D., Bissel, P., Ehrich, M.F. and David Kingston, G.I. (2018) Synthesis and Evaluation of Doxorubicin-Loaded Gold Nanoparticles for Tumor-Targeted Drug Delivery. Bioconjugate Chemistry, 29, 420-430. https://doi.org/10.1021/acs.bioconjchem.7b00756

11. Cui, T., Liang, J.J., Chen, H., Geng, D.D., Jiao, L., Yang, J.Y., Qian, H., Zhang, C. and Ding, Y. (2017) Performance of Doxorubicin-Conjugated Gold Nanoparticles: Regulation of Drug Location. ACS Applied Materials \& Interfaces, 9, 8569-8580. https://doi.org/10.1021/acsami.6b16669

12. Chugh, H., Sood, D., Chandra, I., Tomar, V., Dhawan, G. and Chandra, R. (2018) Role of Gold and Silver Nanoparticles in Cancer Nano-Medicine. Journal Artificial Cells, Nanomedicine, and Biotechnology, 46, 12101220. https://doi.org/10.1080/21691401.2018.1449118

13. Weaver, C.L., La Rosa, J.M., Luo, X. and Cui, X.T. (2014) Electrically Controlled Drug Delivery from Graphene Oxide Nanocomposite Films. ACS Nano, 8, 1834-1843. https://doi.org/10.1021/nn406223e

14. Laurent, S., Saei, A.A., Behzadi, S., Panahifar, A. and Mahmoudi, M. (2014) Superparamagnetic Iron Oxide Nanoparticles for Delivery of Therapeutic Agents: Opportunities and Challenges. Expert Opinion on Drug Delivery, 11, 1449-1470. https://doi.org/10.1517/17425247.2014.924501

15. Cai, X.L., Luo, Y.N., Zhang, W.Y., Du, D. and Lin, Y.H. (2016) pH-Sensitive ZnO Quantum Dots-Doxorubicin Nanoparticles for Lung Cancer Targeted Drug Delivery. ACS Applied Materials \& Interfaces, 8, 22442-22450. https://doi.org/10.1021/acsami.6b04933

16. Mishra, P.K., Mishra, H., Ekielski, A., Talegaonkar, S. and Vaidya, B. (2017) Zinc Oxide Nanoparticles: A Promising Nanomaterial for Biomedical Applications. Drug Discovery Today, 22, 1825-1834.

https://doi.org/10.1016/j.drudis.2017.08.006

17. Li, J., Guo, D., Wang, X., Wang, H., Jiang, H. and Chen, B. (2010) The Photodynamic Effect of Different Size ZnO Nanoparticles on Cancer Cell Proliferation in Vitro. Nanoscale Research Letters, 5, 1063-1071.

https://doi.org/10.1007/s11671-010-9603-4

18. Wang, B., Feng, W. and Wang, M. (2008) Acute Toxicological Impact of Nano- and Submicro-Scaled Zinc Oxide Powder on Healthy Adult Mice. Journal of Nanoparticle Research, 10, 263-276.

https://doi.org/10.1007/s11051-007-9245-3

19. Arakelova, E., Parvanyan, V., Grigoryan, F., Asatryan, G. and Petrosyan, G. (2006) Increase in Concentration of a Zn-Containing Volatile Complex by UV Irradiation of a Target for ZnO Films Synthesis. EPD Congress, TMS ( The Minerals, Metals \& Materials Society), 813-818.

20. Arakelova, E., Grigoryan, F., Parvanyan, V. and Asatryan, G. (2006) Study of Decomposition Regularities for a Zn-Containing Volatile Complex Used in ZnO Film Synthesis. EPD Congress, TMS (The Minerals, Metals \& Materials Society), 883-888.

21. Parvanyan, V.G., Grigoryan, F.A., Arakelova, E.R., Asatryan, G.G., Mirzoyan, G.N. and Petrosyan, G.G. (2007) Formation and Decomposition of a Volatile Zn-Containing Complex for the Synthesis of ZnO Films. Kinetics and Catalysis, 48, 636-639. https://doi.org/10.1134/S0023158407050060

22. Arakelova, E., Khachatryan, A., Avdjyan, K., Voskanyan, A., Farmazyan, Z., Mirzoyan, A., Jivanshiryan, T., Savshenko, L., Ghazaryan, S., Grigoryan, K. and Arsenyan, F. (2010) European Conference on Nano Films. 
March 22-25, Liege, Abstract 78.

23. Arakelova, E., Khachatryan, A., Avjyan, K., Farmazyan, Z., Mirzoyan, A., Savchenko, L., Ghazaryan, S. and Arsenyan, F. (2010) Zinc Oxide Nanocomposites with Antitumor Activity Natural Science. Natural Science, 2, 1341-1348. https://doi.org/10.4236/ns.2010.212163

24. Arakelova, E.R., Grigoryan, S.G., Khachatryan, A.M., Avjyan, K.E., Savchenko, L.M. and Arsenyan, F.G. (2013) New Drug Delivery System for Cancer Therapy. International Journal of Medical Science and Engineering, 7, 1075-1080.

25. Arsenyan, F.G., Muradyan, R.E., Gasparyan, G.V., Arakelova, E.R., Farmazyan, Z.M., Khachatryan, A.M. and Grigoryan, S.G. (2013) Antitumor Activity of Doxorubicin Zinc Oxide Compositions. Blood, 1, 90-94.

26. Arakelova, E.R., Grigoryan, S.G., Farmazyan, Z.M., Khachatryan, A.M. and Arsenyan, F.G. (2014) New Anticancer Drug Delivery System. 5th International Congress Nanotechnology, Medicine \& Biology, Krems, 26-28 March 2014, 7.

27. Arakelova, E.R., Grigoryan, S.G., Arsenyan, F.G., Babayan, N.S., Grigoryan, R.M. and Sarkisyan, N.K. (2014) In Vitro and in Vivo Anticancer Activity of Nanosize Zinc Oxide Composites of Doxorubicin. International Journal of Medical, Pharmacetical Science and Engineering, 8, 38-43.

28. Subedi, D.P., Madhup, D.K., Sharma, A., Joshi, U.M. and Huczko, A. (2011) Study of the Wettability of ZnO Nano Films. International Nano Letters, 1, 117-122.

29. El-Sayyad, H.I., Ismail, M.F., Shalaby, F.M., Abou-El-Magd, R.F., Gaur, A., Fernando, R.L., Raj Madhwa, H.G. and Ouhtit, A. (2009) Histopathological Effects of Cisplatin, Doxorubicin and 5-Flurouracil on the Liver of Male Albino Rats. International Journal of Biological Sciences, 5, 466-473. https://doi.org/10.7150/ijbs.5.466 